\title{
The European Register of Specialists in Clinical Chemistry and Laboratory Medicine: Guide to the Register, Version 3-2010
}

\author{
Janet McMurray ${ }^{1, *}$, Simone Zérah², Michael \\ Hallworth $^{3}$, Peter Schuff-Werner ${ }^{4}$, Alexander \\ Haushofer ${ }^{5}$, Thomas Szekeres ${ }^{6}$, Pierre Wallemacq ${ }^{7}$, \\ Kamen Tzatchev ${ }^{8}$, Charis Charilaou', Jaroslav \\ Racek $^{10}$, Anders Johnsen ${ }^{11}$, Karel Tomberg ${ }^{12}$, Aimo \\ Harmoinen $^{13}$, Hannsjörg Baum ${ }^{14}$, Demetrios Rizos ${ }^{15}$, \\ Janos Kappelmayer ${ }^{16}$, John O'Mullane ${ }^{17}$, Giuseppe \\ Nubile $^{18}$, Silvija Pupure ${ }^{19}$, Zita Kucinskiene ${ }^{20}$, \\ Matthias Opp ${ }^{21}$, Rob Jansen ${ }^{22}$, Bogdan Solnica ${ }^{23}$, \\ Henrique Reguengo ${ }^{24}$, Camelia Grigore ${ }^{25}$, Július \\ Špaňár ${ }^{26}$, Greta Štrak ${ }^{27}$, Josep Queralto ${ }^{28}$, Hans \\ Wallinder $^{29}$ and Gijsbert Wieringa ${ }^{30}$ \\ ${ }^{1}$ Association for Clinical Biochemistry, London, UK \\ ${ }^{2}$ Laboratoire ZTP, Bagnolet, France (SFBC France) \\ ${ }^{3}$ Department of Clinical Biochemistry, Royal Shrewsbury \\ Hospital, Shrewsbury, UK \\ ${ }^{4}$ Institute for Clinical Chemistry and Laboratory Medicine, \\ University of Rostock, Rostock, Germany \\ ${ }^{5}$ Österreichische Gesellschaft für Laboratoriumsmedizin \\ und Klinische Chemie, Vienna, Austria \\ ${ }^{6}$ General Hospital Vienna, KIMCL 5H, Vienna, Austria \\ ${ }^{7}$ Laboratory of Toxicology, Cliniques Universitaires St. \\ Luc, Brussels, Belgium \\ ${ }^{8}$ Department of Clinical Laboratory and Clinical \\ Immunology, Medical University, Sofia, Bulgaria \\ ${ }^{9}$ Association of Clinical Directors, Biomedical Scientists \\ and Clinical Laboratory Scientists, Nicosia, Cyprus \\ ${ }^{10}$ Institute of Clinical Biochemistry and Haematology, \\ Charles University Hospital, Plzen, Czech Republic \\ ${ }^{11}$ Department of Clinical Biochemistry, National University \\ Hospital, Copenhagen, Denmark \\ ${ }^{12}$ North Estonian Regional Hospital, Tallin, Estonia \\ ${ }^{13}$ Savonlinnan keskussairaala Laboratorio, Savonlinna, \\ Finland \\ ${ }^{14}$ Institut für Laboratoriumsmedizin, Regionale Kliniken \\ Holding RKH GmbH, Ludwigsburg, Germany \\ ${ }^{15}$ Hormone Laboratory, "Aretaieion" University Hospital, \\ Athens, Greece \\ ${ }^{16}$ Department of Clinical Biochemistry and Molecular \\ Pathology, University of Debrecen, Debrecen, Hungary \\ ${ }^{17}$ Department of Clinical Biochemistry, Cork University \\ Hospital, Cork, Ireland \\ ${ }^{18}$ Laboratorio Analisi, Ospedale G. Bernabeo di Ortona, \\ Ortona, Italy
}

*Corresponding author: Janet McMurray, EC4 Register Commission, c/o Association for Clinical Biochemistry, 130-132 Tooley Street, London SE1 2TU, UK

Phone: +44-20-7403-8001, Fax: +44-20-7403-8006,

E-mail: enquiries@ACB.org.uk

Received February 16, 2010;

previously published online April 21, 2010

\author{
${ }^{19}$ Clinical Hospital “Gailefers”, Riga, Latvia \\ ${ }^{20}$ Department of Physiology, Biochemistry and Laboratory \\ Medicine, Vilnius University, Vilnius, Lithuania \\ ${ }^{21}$ Laboratoire National de Santé, Luxembourg, \\ Luxembourg \\ ${ }^{22}$ SKML, Nijmegen, The Netherlands \\ ${ }^{23}$ Department of Clinical Biochemistry, Jegiellonien \\ University Medical College, Krakow, Poland \\ ${ }^{24}$ Sociedade Portuguesa de Quimica Clinica, Porto, \\ Portugal \\ ${ }^{25}$ Laborator Spitalul Clinic de Pediatrie Sibiu, University \\ Hospital, Sibiu, Romania \\ ${ }^{26}$ Slovak Society of Clinical Biochemistry, Trnava, \\ Slovakia \\ ${ }^{27}$ Department of Laboratory Diagnostics, General Hospital \\ Murska Sobota, Murska Sobota, Slovenia \\ ${ }^{28}$ Servicio de Bioquimica, Hospital Santa Creu I San Pau, \\ Barcelona, Spain \\ ${ }^{29}$ Department of Clinical Chemistry, Aleris Medilab, Taby, \\ Sweden \\ ${ }^{30}$ Department of Clinical Chemistry, Royal Bolton \\ Hospital, Bolton, UK
}

\begin{abstract}
In 1997, the European Communities Confederation of Clinical Chemistry and Laboratory Medicine (EC4) set up a Register for European Specialists in Clinical Chemistry and Laboratory Medicine. The operation of the Register is undertaken by a Register Commission (EC4RC). During the last 12 years, more than 2200 specialists in Clinical Chemistry and Laboratory Medicine have joined the Register. In 2007, EC4 merged with the Forum of European Societies of Clinical Chemistry and Laboratory Medicine (FESCC) to form the European Federation of Clinical Chemistry and Laboratory Medicine (EFCC). Two previous Guides to the Register have been published, one in 1997 and another in 2003. The third version of the Guide is presented in this article and is based on the experience gained and development of the profession since the last revision. Registration is valid for 5 years and the procedure and criteria for re-registration are presented as an Appendix at the end of the article.

Clin Chem Lab Med 2010;48:999-1008.
\end{abstract}

Keywords: Clinical Chemistry and Laboratory Medicine; continuing education; continuing professional development; EurClinChem; European Register; registration; re-registration; training. 


\section{Introduction}

The European Communities Confederation of Clinical Chemistry and Laboratory Medicine (EC4) established a Register of Specialists in Clinical Chemistry and Laboratory Medicine in 1997 in order to promote recognition of the profession. The Register ensures common standards of education, training, experience and compliance, as well as continuous professional development of the registrants. The first and second versions of the Guide to the Register were published in 1997 and 2003, respectively $(1,2)$. The Guide to the Register gives the minimum standards of clinical chemistry education and training, organises the operation of the register and defines the procedures. The Syllabus (3) describes the depth and breadth of clinical chemistry and laboratory medicine knowledge and experience to be achieved for professional competence. A Register Commission (EC4RC) was formed including delegates from each member state of the European Union and started work in 1998. It set up the organisation of the workflow and the application process. The registration process started in September 1998, when the first European Specialists were accepted. Today, there are more than 2200 specialists on the Register from 20 out of the 27 EU countries.

Following the expansion of the European Union from 15 countries to 25 countries in 2004, and then to 27 countries in 2007, EC4 merged with the Forum of European Societies of Clinical Chemistry and Laboratory Medicine (FESCC) in 2007 to form the European Federation of Clinical Chemistry and Laboratory Medicine (EFCC). EFCC is now the European Regional Organisation of the International Federation of Clinical Chemistry and Laboratory Medicine (IFCC). The EC4RC remains a part of EFCC with responsibility for the operation of the EC4 European Register of Specialists in Clinical Chemistry and Laboratory Medicine.

As the operation of the Register progressed, it became necessary to develop procedures and to establish some definitions. These changes had no influence on the level of evaluation but optimised the work of the EC4RC. These alterations are part of the updated Guide to the Register presented here.

Countries having a national education and training programme and a national register are able to present their education standards to EC4RC. If the national conditions meet the EC4RC requirements, equivalence of standards is agreed by the EC4RC and the applications follow a simple procedure. Applicants should both conform to the EC4RCapproved national equivalence of standards and be a member of their national register, where one exists.

The appointment of the chairman and secretary of EC4RC and their terms of office are defined, as well as the members of the Committee of Appeal and their term of office. The Code of Conduct was updated in 2008 (4).

Registration is valid for 5 years. The re-registration procedure is defined and included in this paper. For re-registration, two main conditions are required; applicants have to continue their practice as clinical chemists and they have to participate in a continuing professional development programme. These programmes are evolving at the national level and the applicant has to follow the national scheme.

\section{References}

1. Sanders GT, Kelly AM, Breuer J, Kohse KP, Mocarelli P, Sachs C, et al. The European Register for Clinical Chemists. Eur J Clin Chem Clin Biochem 1997;35:795-803.

2. Gurr E, Koller U, Blaton V, Lund E, Harmoinen A, Zérah S, et al. The European Register for Specialists in Clinical Chemistry and Laboratory Medicine: Guide to the Register version 2-2003 and Procedure for Re-registration. Clin Chem Lab Med 2003;41: 238-47.

3. Zérah S, McMurray J, Bousquet B, Baum H, Beastall G, Blaton V, et al. EC4 European Syllabus for Post-Graduate Training in Clinical Chemistry and Laboratory Medicine: Version 3-2005. Clin Chem Lab Med 2006;44:110-20.

4. McMurray J, Zérah S, Hallworth M, Koeller U, Blaton V, Tzatchev K, et al. The European Register of Specialists in Clinical Chemistry and Laboratory Medicine: Code of Conduct, Version 2-2008. Clin Chem Lab Med 2009;47:372-5. 


\section{Guide to the European Register of Specialists in Clinical Chemistry and Laboratory Medicine: European Clinical Chemist: Version 3-2010}

3rd revision: approved at the EC4 Register Commission meeting in Paris, on 5 November 2009.

\section{Contents}

I. Introduction

1.0 Clinical Chemistry and Laboratory Medicine

2.0 EC4 and EFCC

2.1 Objectives

II. The EC4 Register

3.0 Premise

4.0 Professional training

5.0 Minimum standards

5.1 Minimum standards to enter speciality training

5.2 Minimum standards for registration as a European Clinical Chemist

5.3 Evolution of Clinical Chemistry

6.0 Title

7.0 Competencies

8.0 National registers

9.0 Code of Conduct

III. Operation of the Register

10.0 EC4/EFCC bodies

10.1 The EC4 Register Commission, EC4RC

10.2 The National Clinical Chemistry Register

Committees, NCCRCs

10.3 The EC4 Committee of Appeal, EC4CA

10.4 Custody of the EC4 Register

IV. Procedures

11.0 Application

11.1 Validation of applications

11.1.1 EU citizens trained within the EU

11.1.2 EU citizens trained outside the EU

11.1.3 Non-EU citizens

11.2 Registration as a European Specialist in Clinical

Chemistry and Laboratory Medicine

11.3 Certificates

11.4 Renewal of registration

11.5 Finances

V. Points of contention

12.0 Cases of Doubt

VI. Procedure for Re-registration

13.0 Six Elements of Re-registration

13.1 Re-registration Application form and Process

References

Appendix 1: Continuing Education (CE) or Continuing Professional Development (CPD)

\section{Introduction}

\subsection{Clinical Chemistry and Laboratory Medicine}

The name Clinical Chemistry will be used throughout this document, according to the definition of the International Federation of Clinical Chemistry and Laboratory Medicine (IFCC). The speciality is defined as follows:

"Clinical Chemistry and Laboratory Medicine is the application of chemical, molecular and cellular concepts and techniques to the understanding and evaluation of human health and disease. At the core of the discipline is the provision of results of measurements and observations to the cause of disease, the maintenance of health and the conversion of these data into specific and general patient- and disease-related information at the laboratory-clinician interface. The discipline is committed to deepening understanding of health and disease through fundamental and applied research"' (1).

In addition, it is stated that "Clinical Chemistry is the largest subdiscipline of Laboratory Medicine which is a multidisciplinary medical and scientific speciality with several interacting subdisciplines, such as haematology, immunology, clinical biochemistry, and others. Through these activities clinical chemists influence the practice of medicine for the benefit of the public', (2).

In many countries, the practice of Clinical Chemistry includes components of microbiology, haematology, molecular biology and immunology as well as traditional clinical biochemistry. Clinical Chemists are responsible for comprehensive laboratory services including, for example, provision of clinical interpretation and advice, management, quality assurance and informatics. They frequently conduct research in laboratory medicine. For these reasons their professional education needs to include scientific, analytical, clinical, research skills and management training combined with informatics.

Where "analysis" is referred to, the complete analytical process, including pre- and post-analytical phases, is included.

In different member states of the European Union (EU) the designation for Clinical Chemistry appears either by speciality designation of Clinical Chemistry or associated with, or included in, other specialities under a broader designation.

The designations for the speciality in the member states of the EU are:

Austria Medizinische Chemie, Laboratoriumdiagnostik

Belgium Biologie Clinique/Klinische Biologie 


$\begin{array}{ll}\text { Bulgaria } & \text { Clinical Laboratory } \\ \text { Czech Republic } & \text { Klinická Biochemie } \\ \text { Cyprus } & \text { Laboratory Medicine/Clinical Chemistry } \\ \text { Denmark } & \text { Klinisk Biokemi } \\ \text { Estonia } & \text { Laboratory Medicine } \\ \text { Finland } & \text { Kliininen Kemia } \\ \text { France } & \text { Biologie Médicale } \\ \text { Germany } & \text { Klinische Chemie, Laboratoriumsmedizin } \\ \text { Greece } & \text { Klinikè Chimeia - Klinikè Biochimeia } \\ \text { Hungary } & \text { Orvosi Laboratoriumi Diagnosztika } \\ & \text { (Medical Laboratory Diagnostics/Laboratory } \\ & \text { Medicine) } \\ \text { Ireland } & \text { Clinical Biochemistry } \\ \text { Italy } & \text { Patologia Clinica/Laboratory Medicine } \\ \text { Latvia } & \text { Laboratorâ Medicina } \\ \text { Lithuania } & \text { Laboratorine Medicina/Medicinos Biologija } \\ \text { Luxembourg } & \text { Biologie Clinique/Biochemie } \\ \text { Malta } & \text { Patologija Kimika (Chemical Pathology) } \\ \text { Netherlands } & \text { Klinische Chemie en Laboratorium Geneeskunde } \\ \text { Poland } & \text { Diagnostyka Laboratoryjna } \\ \text { Portugal } & \text { Analises Clinicas/Patologia Clinica } \\ \text { Romania } & \text { Laboratory Medicine } \\ \text { Slovakia } & \text { Klinická Biochémia } \\ \text { Slovenia } & \text { Medicinska Biokemija } \\ \text { Spain } & \text { Bioquimica Clinica - monovalent } \\ \text { Sweden } & \text { Análisis Clínicos - polyvalent } \\ \text { UK } & \text { Klinisk Kemi } \\ & \text { Clinical Biochemistry/Chemical Pathology } \\ & \end{array}$

Thus Clinical Chemists are medical laboratory specialists having knowledge of, expertise in, and responsibility for, a broad spectrum of diagnostic laboratory investigations.

\subsection{EC4 and EFCC}

Until 2007, the European Communities Confederation of Clinical Chemistry and Laboratory Medicine (3) was the organisation linking all national IFCC-recognised clinical chemistry societies within the different member states of the European Union. It was founded in 1973 and its constitution formalised in 1993. The Articles of Association were drawn up in Amsterdam in September 2002. The Forum of European Societies of Clinical Chemistry and Laboratory Medicine (FESCC) was the European section of the IFCC and was composed of the IFCC-recognised clinical chemistry societies from the whole of Europe, as defined by the World Health Organisation. With the expansion of the European Union from 15 to 25 member states in 2004, and to 27 in 2007, the geographical differences between EC4 and FESCC diminished and the two organisations merged in 2007, forming the European Federation of Clinical Chemistry and Laboratory Medicine (EFCC) (4) which is now the European Regional Organisation of the IFCC. The EC4 Register Commission (EC4RC) remains a sub-section of EFCC with responsibility for the European Register of Specialists in Clinical Chemistry and Laboratory Medicine. EC4 is established as a Foundation under Netherlands law and the EC4 Foundation Board and the Professional Committee oversee the EC4 Register Commission under the direction of the Executive Board of EFCC (Figure 1).

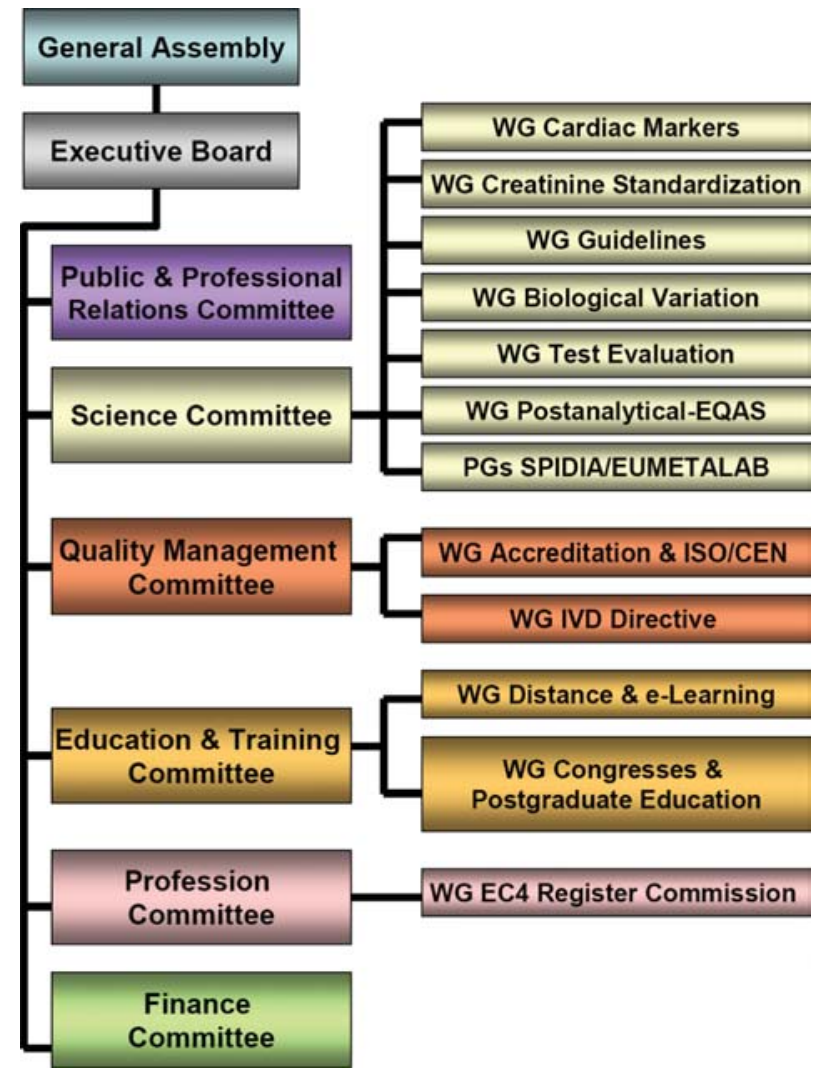

Figure 1 EFCC Organisational Structure showing the relationship of the EC4 Register Commission to the EFCC Executive Board.

\subsection{Objectives}

The present objectives of the EC4 Register Commission are:

a. to promote the advancement of Clinical Chemistry within the EU to the European Commission, European citizens and the medical profession, and to do all such things as may in the opinion of the Foundation Board of EC4 spread or increase the knowledge and standing of Clinical Chemistry within the EU, in cooperation with EFCC and IFCC;

b. to promote the regulation of the profession of Clinical Chemistry in the EU by maintaining a register and by furthering the establishment of a "Common Platform", within the framework of the EU system of Directives regarding professional recognition, describing the discipline and the standards of education, training and experience required to achieve "Registered Clinical Chemist' status;

c. to coordinate the automatic and mutual recognition of European Clinical Chemists on the basis of equivalence of standards and to promote the recognition of, and to protect, the European Clinical Chemist title;

d. to cooperate with any examining body in a clinical or basic science subject in promoting suitable qualifying examinations for members of the profession of Clinical Chemistry; 
e. to foster high standards of continuous professional development and education, and to introduce related requirements for re-registration in the Register.

\section{The EC4 Register}

\subsection{Premise}

In each member state, laboratory medicine is organised within its own national health care system. The EC4RC respects these different structures and has created a Register based on a Syllabus (5) for postgraduate training in order to:

a. guarantee that the minimum requirements for the education and training of the individual clinical chemist have been fulfilled for the benefit of the individual patient and of health care in general;

b. facilitate the comparability of professional training of clinical chemists within the EU by establishing a framework of mutual recognition of qualifications, and facilitate the free movement of practitioners in order to provide clinical chemists who wish to practise outside their country with a guarantee of ability;

c. encourage continuous improvement in the quality of Clinical Chemistry and its practitioners by setting, monitoring and reviewing standards for the definition and practice of Clinical Chemistry in the EU;

d. provide a source of information about the different systems of education and training in the member states.

\subsection{Professional training}

EC4RC has judged the respective values of the education and professional training systems in the EU and has developed a Syllabus comprising all the subjects necessary to achieve a high level of professional competence. The European Syllabus for postgraduate training in Clinical Chemistry (5) describes the minimum scientific and professional knowledge, recognising the responsibility of each member state for organising laboratory medicine within its own health care system. Thus, although significant differences exist in the practice of Clinical Chemistry across the EU, a large number of core elements can be discerned. These are considered to be the minimum scientific requirements for those who want to be registered as a specialist. The attainment of these competences is the threshold which opens the right to registration. Since in most cases the professional activities include management responsibilities, it is important that the subjects of laboratory organisation and management are included in the training period.

The specialist who is registered on the basis of the above standards not only fulfils the professional objectives of the EC4RC, but is also competent to be the head of a laboratory, one of the conditions necessary for its accreditation under ISO 15189 (6).

\subsection{Minimum standards}

The education in all the EU countries is based on a broadly identical scheme. It comprises a university education, followed by speciality training in Clinical Chemistry. The standards stipulated below are the minimum required for admission to the Register.

\subsection{Minimum standards to enter speciality training}

The minimum standard to enter speciality training is a university degree in medicine, chemistry, biochemistry, pharmacy, or another relevant basic science subject, which allows entry to postgraduate speciality training.

\subsection{Minimum standards for registration as a European Clinical Chemist}

The minimum standard for registration as a European Clinical Chemist is a total of 9 years university and postgraduate study. A minimum of 4 years postgraduate study after gaining a university degree must be spent on specialist training in a laboratory in a medical environment, approved and supervised by the national body functioning for that purpose within the health care system of the member state.

\subsection{Evolution of Clinical Chemistry}

In a number of countries within the EU there is an increasing trend for Clinical Chemistry to encompass several disciplines. As a result, the professional training can be multidisciplinary (i.e., Clinical Chemistry and for example Haematology, Immunology etc.) as well as in a single discipline (e.g., Clinical Biochemistry). Training could be multidisciplinary initially, followed by specialisation, provided the basic training includes clinical chemistry in accordance with the Syllabus sections 1: i-viii, A:1-24 (5). In all cases the conditions as specified in Section 5.2 apply.

\subsection{Title}

Registration as a "European Specialist in Clinical Chemistry and Laboratory Medicine'" gives the right to be called European Specialist in Clinical Chemistry and Laboratory Medicine in the language of the member state and to use the professional title European Specialist in Clinical Chemistry and Laboratory Medicine, abbreviated EurClinChem (invariable in all member states) with the national title, if lawful.

\subsection{Competencies}

Clinical Chemists having obtained registration in the EC4 European Register for Specialists in Clinical Chemistry and Laboratory Medicine should be aware of their professional responsibilities and should have achieved competence in the following:

a. understanding of the registrant's responsibility in the practice of his/her profession to the well-being and personal safety of his patients, colleagues, co-workers, the community, and the environment; 
b. thorough knowledge of all aspects of clinical laboratory sciences relevant to the discipline practised as specified in the Syllabus (Section 4.0);

c. ability to obtain, explore, and employ knowledge and methods of investigation in the interest of health care and humankind;

d. broad knowledge of, and insight into, biochemical processes in human health and disease on a general and patient-specific level;

e. ability to work in a multidisciplinary environment and function as a consulting advisor to his/her clinical colleagues and liaise with them in the choice of tests and the interpretation of laboratory results;

f. ability to safeguard and protect the public against misuse of medical laboratory investigations;

g. knowledge of the principles of management leading to satisfactory direction, supervision, and organisation of a laboratory department in a public or private hospital or in any other health care environment resulting in the provision of a competent service as laid down in a laboratory quality manual, based on good laboratory services as defined in EN-ISO document 15189 and the EC4 Essential Criteria (6-9);

h. ability to assess conflicting and various technical, financial, and human considerations (e.g., care, quality, safety, cost, and time scales) both in the short- and long-term, and to find the optimal solution in relation to patient care;

i. ability to apply current techniques in human resource management;

j. ability to communicate orally and in writing, including the production of clear, cogent reports and publications in refereed international scientific journals;

k. knowledge of, and insight into, the use of technology and analytical techniques relevant to the field of specialisation, an active appreciation of developments, and an attitude of innovation and creativity in their implementation in the profession of Clinical Chemistry;

1. ability to take responsibility for the data and information produced, including knowledge of the influence of variation (biological as well as analytical) on interpretation of data;

m. appreciation of developments both in science and technology and also in the understanding of disease in order to ensure the appropriate use of laboratory investigations and to optimise the advice provided on those investigations (see also ref. 5);

n. ability to conduct research, either basic or applied, in order to further knowledge in the field of Clinical Chemistry and Laboratory Medicine.

\subsection{National registers}

The EC4RC acknowledges the national registers as they function in the member states provided that they are in accordance with the minimum standards and are based on the curriculum, so that it is possible for candidates to develop towards professional competence as described in Section 4.
Applicants should both conform to the EC4RC-approved national equivalence of standards for registration and be a member of their national register, where one exists. In those member states where Clinical Chemistry training is not presently organised according to the defined requirements, the EC4RC (Section 10.1) and the National Registration Committees (Section 10.2) need to ensure that standards required for each national register meet the minimum standards required for the EC4 Register.

\subsection{Code of Conduct}

The EC4RC has developed a Code of Conduct (10) which all applicants to the Register must agree to abide by. This Code of Conduct does not over-ride any codes of practice in place with national registers or national societies.

\section{Operation of the Register}

\subsection{EC4/EFCC bodies}

The EC4 Foundation Board and the EC4 Register Commission (Section 10.1) are responsible for the Register and for modification of the standards in the light of changing technology and other developments, under the supervision of the EFCC Board and its Professional Committee. Standards are accordingly reviewed at regular intervals of not more than 5 years.

The EC4 Register is maintained by the EC4RC (Section 10.1) and is administered by the EC4 Secretariat which keeps records of the registrations. Whenever possible, the EC4RC will seek the advice of the National Clinical Chemistry Register Committees (NCCRCs) (Section 10.2), in making its decisions.

\subsection{The EC4 Register Commission, EC4RC}

The Register Commission is composed of one representative from each member state, preferably a member of the NCCRC, and members of the Board of EFCC. National Representatives should be mandated members of the national society recognised by the IFCC but they need not be officers of that society. The representatives should be registered European Clinical Chemists, if possible. If more than one NCCRC exists in a member state, e.g., for different academic origins, the National Representative should be a joint representative.

The Chairman and Secretary of the EC4 Register Commission are appointed by the EFCC Board and the Chairman is in this capacity a co-opted member of the EFCC Board. The term of office for both the Chairman and the Secretary is 3 years with a maximum of two terms.

- The EFCC Board appoints two of its members to represent the Board on the EC4RC.

- The EC4RC decides on minimum requirements for registration and re-registration.

- The EC4RC decides on the granting of Equivalence of Standards of the national training programme to National 
Registers, including the level of admission to the programme.

- The EC4RC decides on the eligibility of candidates for registration and re-registration.

- The EC4RC provides its members annually with statistical information about the number of new registrations from the different member states.

\subsection{The National Clinical Chemistry Register Committees, NCCRCs}

The National Clinical Chemistry Register Committees, NCCRCs, are national bodies composed of representatives from the national clinical chemistry societies and the government, or any other body recognised for the purpose in that member state. It is the responsibility of these Committees to keep EC4RC well informed on the national education structure.

The NCCRC assesses whether applicants from that member state meet the equivalence of standards. It may or may not be the responsible body for national registration. Applicants approved by their NCCRC may then apply to EC4RC to be recognised as European Specialists.

Applications for the EC4 Register are sent to the NCCRC. The NCCRC checks whether the applicant fulfils the national requirements. The NCCRC sends the application accompanied by its advice to the EC4RC Secretariat.

The NCCRC is responsible for checking that the application fee to the Register is paid according to agreed procedure(s), prior to forwarding the application.

\subsection{The EC4 Committee of Appeal, EC4CA}

The EC4 Committee of Appeal (EC4CA), is a European body composed of five independent experts from representative member states. Committee members are proposed by the NCCRCs and appointed by the EFCC Board. Their term of office is a maximum of 5 years. EC4CA elects a chairman responsible to the EC4RC and individual applicants. EC4CA acts on behalf of the EFCC Board in adjudicating on applicants who appeal against a decision of EC4RC not to grant registration. The EC4CA also advises the EC4RC on equivalence when applicants have not followed standard education or training programmes.

\subsection{Custody of the European Register}

The European Register is kept by the EC4RC. The computer database is maintained by a commercial company under contract.

\section{Procedures}

\subsection{Application}

Application is open only to individuals who have the required qualifications, i.e., they must have trained and/or be registered in an EU country. Application for registration is made on-line on the EC4 Register website (11) followed by a paper copy of the application form and relevant documents being sent to the NCCRC.

\subsection{Validation of applications}

11.1.1 EU citizens trained within the EU As a general rule, an EU citizen who has professional registration as a clinical chemist in an EU country is automatically eligible for registration by EC4RC, if the national register and training programme have been granted equivalence of standards. It is the responsibility of the NCCRC of the country of registration to check the validity of his/her university education (as specified in 5.1) and professional training. Consequently, the minimum EC4 requirements have then been fulfilled (Sections 5.2 and 5.3).

An EU citizen who is not residing and registered in an EU country but was trained within the EU can apply for EC4 registration via the NCCRC of the country in which they were trained. It is the responsibility of the NCCRC to check the validity of his/her university education and professional training (see previous paragraph).

All applications must be accompanied by a statement from the NCCRC of the country of registration and/or training supporting the applicant and stating that the applicant has the necessary qualifications for registration as a European Clinical Chemist. If the education and training are assessed as adequate it would be assumed that the applicant has achieved competence as defined in Section 7.0.

11.1.2 EU citizens trained outside the EU EU citizens trained outside the EU and registered in an EU country can be considered for EU registration only if they have undergone a university education and professional training which meet the EC4 criteria. It is for the NCCRC of the country of registration to provide the EC4RC with the evidence that the candidate meets the Equivalence of Standards. The final decision is with the EC4RC. The EC4RC does not give general decisions on the equivalence of diplomas or degrees accepted in EU member states.

11.1.3 Non-EU citizens Non-EU citizens may be eligible for registration only if the education and training of the applicant has taken place in an EU country according to the predefined conditions. The NCCRC of the country of training and, when different, of the country of registration, must support the application.

Non-EU citizens not trained or registered in an EU country are not eligible for registration.

\subsection{Registration as a European Specialist in Clinical Chemistry and Laboratory Medicine}

The EC4RC decides on the basis of Sections 11.0 and 11.1 the eligibility of applicants for registration. Successful applicants are then included in the Register. 
Persons registered as European Specialists in Clinical Chemistry and Laboratory Medicine must abide by the EC4/ EFCC Code of Conduct (10).

Any application not approved will be returned to the NCCRC and reasons for rejection will be given. Such applicants have the right to appeal the decision and they can submit their case to the EC4 Committee of Appeal within a defined time period.

\subsection{Certificates}

Registration as a European Specialist in Clinical Chemistry and Laboratory Medicine is attested by a certificate which is prepared by the Secretariat and signed by the Chairman of the EC4RC and an EFCC Board member.

\subsection{Renewal of registration}

Continuing registration as a European Specialist in Clinical Chemistry and Laboratory Medicine is dependent on the registrant remaining in practice and observing the EC4/EFCC Code of Conduct (10).

Registration should be renewed every 5 years through the relevant NCCRC.

\subsection{Finances}

EFCC/EC4RC and each individual national Clinical Chemistry society bear the costs of the administrative work involved in operating the Register and are entitled to recover these costs by charging a fee to applicants. EFCC and EC4RC are non-profit making bodies.

\section{Points of contention}

\subsection{Cases of doubt}

All cases of doubt or difficulty, relating to the decision on individual applications, are referred to the EC4 Committee of Appeal (see 10.3) for decision. An individual may subsequently appeal in writing against this decision to the EFCC Board, whose decision is final and without appeal.

\section{Procedure for re-registration}

\subsection{Six Elements of re-registration}

It has been agreed that there are six elements of reregistration:

1. Continuing equivalence of standards

Re-registration of an individual will normally be via the NCCRC. At 5 yearly intervals, or sooner if change occurs, each NCCRC shall seek formal approval from EC4RC that equivalence of standards for the national register has been maintained. The EC4RC can only confirm re-registration by NCCRCs when it has evidence of continuing equivalence of standards.

2. Continuing registration in the national register

It is a condition of re-registration that each applicant must remain a member of his/her own national register (if one exists). This question is asked on the re-registration application form and the signatures of the applicant and the NCCRC representative are taken as confirmatory evidence.

3. Continuing in active practice

It is a condition of re-registration that each applicant continues to be an active practitioner in Clinical Chemistry and Laboratory Medicine. This will be met if the practitioner is in appropriate full-time employment. There may be circumstances when an individual in part-time employment or between jobs may be considered to be an active practitioner but it is the responsibility of the applicant to produce evidence to this effect. This question is asked on the re-registration application form and the signatures of the applicant and the NCCRC representative are taken as confirmatory evidence.

4. Continuing professional development

It is a condition of re-registration that each applicant is actively engaged in continuing professional development (CPD). There are many different approaches to CPD and the EC4RC cannot be prescriptive in this area beyond the two principles in Appendix 1. Each NCCRC shall obtain approval from the EC4RC of a written statement of how it intends to assess that an applicant is engaged in a programme of CPD that is in line with the guidelines provided in Appendix 1. This question is asked on the re-registration application form and the signatures of the applicant and the NCCRC representative are taken as confirmatory evidence.

5. Continuing observance of the Code of Conduct

It is a condition of re-registration that the applicant continues to observe the EC4/EFCC Code of Conduct (10). This question is asked on the re-registration application form and the signatures of the applicant and the NCCRC representative are taken as acceptance of this condition.

6. Payment of the fee

It is a condition of re-registration that the applicant pays the re-registration fee. This fee is fixed at $80 \%$ of the original registration fee and the current fee is specified on the re-registration application form. The NCCRC is responsible for confirming payment of this fee.

\subsection{Re-registration Application Form and Process}

The re-registration form is on the EC4 Register website (11) and is available to registrants when their registration is due to expire. This is very similar in content and design to the application form for initial registration, the main difference 
being the need to produce evidence of CPD rather than of education, training and experience. Application for re-registration is made on-line with a paper copy of the form and relevant documents being sent to the NCCRC.

The EC4 Register Secretariat notifies NCCRCs of individuals whose registrations are due to expire and NCCRCs inform the individuals of the need to re-register. The practitioner completes and signs the form and submits it with proof of payment to his/her NCCRC in a manner identical to the original application. A counter-signature from a representative of the NCCRC, who has approval for its assessment of CPD, will effectively confer re-registration on the applicant, although this is formalised through the EC4RC using the same mechanism as for initial registration.

Appeals against decisions on re-registration follow the same route as for initial registration.

\section{Conflict of interest statement}

Authors' conflict of interest disclosure: The authors stated that there are no conflicts of interest regarding the publication of this article.

Research funding: None declared.

Employment or leadership: None declared.

Honorarium: None declared.

\section{References}

1. International Federation of Clinical Chemistry and Laboratory Medicine. Handbook 2006. http://www.ifcc.org.

2. International Federation of Clinical Chemistry. Strategic Plan 1996-2000. Int Fed Clin Chem.

3. Sanders GT, Kelly AM, Breuer J, Mocarelli P. The role of European Communities Confederation of Clinical Chemistry (EC4) in the harmonisation of Clinical Chemistry in the European Union. Eur J Clin Chem Clin Biochem 1995;33:947-8.

4. European Federation of Clinical Chemistry and Laboratory Medicine. http://www.efcclm.eu.

5. Zérah S, McMurray J, Bousquet B, Baum H, Beastall G, Blaton V, et al. EC4 European Syllabus for Post-Graduate Training in Clinical Chemistry and Laboratory Medicine: Version 3-2005. Clin Chem Lab Med 2006;44:110-20.

6. ISO 15189:2007. Medical laboratories - particular requirements for quality and competence. International Organization for Standardisation, 2007.

7. Jansen RT, Blaton V, Burnett D, Huisman W, Queralto J, Zérah $\mathrm{S}$, et al. Essential criteria for quality systems in medical laboratories. Eur J Clin Chem Clin Biochem 1997;35:121-32.

8. Jansen RT, Blaton V, Burnett D, Huisman W, Queralto J, Zérah $\mathrm{S}$, et al. Additional essential criteria for quality systems of medical laboratories. Clin Chem Lab Med 1998;36:249-52.

9. Jansen RT, Kenny D, Blaton V, Burnett D, Huisman W, Plebani M, et al. Usefulness of EC4 Essential Criteria for Quality Systems of Medical Laboratories as Guideline to the ISO 15189 and ISO 17025 documents. Clin Chem Lab Med 2000;38:105764.
10. McMurray J, Zérah S, Hallworth M, Koeller U, Blaton V, Tzatchev K, et al. The European Register of Specialists in Clinical Chemistry and Laboratory Medicine: Code of Conduct, Version 2-2008. Clin Chem Lab Med 2009;47:372-5.

11. EC4 Register. http://www.ec4register.eu.

\section{Appendix 1: Continuing Education (CE) or Continuing Professional Development (CPD)}

\section{Two principles}

It is suggested that there should be two principles underpinning programmes of CE or CPD that are suitable for meeting the requirements of re-registration with the European Clinical Chemist Register:

1. The Clinical Chemist must undertake structured $\mathrm{CE}$ or CPD relevant to his/her professional role and be able to produce documentary evidence of ongoing participation.

2. The minimum time commitment to any programme of CE or CPD should be $50 \mathrm{~h} /$ year $(\sim 1 \mathrm{~h} /$ week $)$.

\section{Content of CE or CPD programmes}

The content of CE or CPD programmes will vary between countries. Therefore, the list of activities given below should be seen as purely illustrative:

- Oral presentation of research findings

- Poster presentation of research findings

- Attendance at approved scientific meetings

- Publication of research papers

- Research grants obtained

- Serving as referee or editor for a scientific journal

- Postgraduate teaching including supervision of research students/fellows

- Participation in journal clubs (or similar)

- Evidence of regular reading of relevant scientific or management journals

- Attendance at approved CE or CPD training courses

- Attendance at relevant management courses

- Completion of approved distance learning exercises

- Completion of relevant computer-aided learning programmes

- Completion of relevant clinical audit projects

- Completion of CE or CPD targets in personal development plans (appraisal)

- Being an office bearer in a relevant national or international professional body

- Serving as external examiner or inspector for a university or laboratory

- Being an appointed advisor for government or scientific or regulatory body

- Participating in a successful laboratory accreditation (or similar)

- Serving as an appointed assessor or inspector for an accreditation body 


\section{Documentary evidence}

At a national level there may be a formal CE or CPD scheme that complies with the two principles listed above. In such circumstances the only evidence required for re-registration would be a certificate (or a similar document) confirming ongoing participation in the scheme. In the absence of a formal CE or CPD scheme the NCCRC should specify the level of evidence that it requires for re-registration and include this as part of the application for approval from EC4RC. 